\title{
Kosovo's Ground Flash Density and Protection of Transmission Lines of the Kosovo Power System from Atmospheric Discharges
}

\author{
https://doi.org/10.3991/ijes.v6i1.8434 \\ Bahri Prebreza, Bujar Krasniqi $\left({ }^{\bowtie}\right)$ \\ University of Prishtina, Prishtina, Kosovo \\ bujar.krasniqi@uni-pr.edu
}

\begin{abstract}
In this paper is presented the protection of transmission power lines of the Kosovo Power System from atmospheric discharges, with the use of surge arresters. Atmospheric discharges represent one of the main causes of interruptions for the Kosovo Power System. In addition, the ground flash density for Kosovo is given. The transmission lines with the worst performance regarding atmospheric discharges are discussed in more detail and are presented recommendations about the surge arresters used to protect the system from these overvoltages. The data provided by the localized lightning system in Kosovo enable us to provide a detailed correlation of the reported outages of the Kosovo Power System and corresponding atmospheric discharges. Recommendations for protection in terms of surge arresters are given, followed by subsequent dynamic simulations using MATLAB software.
\end{abstract}

Keywords-Atmospheric discharges, ground flash density, surge arresters, Kosovo Power System, MATLAB.

\section{Introduction}

The power system of a country and its regular operation is of high importance for a country, both in social and economic aspects. Power outages affect the daily human activities and the economic performance of a country. This is evident with the close relation of gross domestic production (GDP) on the one side and power supply on the other. Depending on the mode and time of the occurrence, all overvoltages are divided into atmospheric, internal and induced overvoltages. Whenever the overvoltages are present in power systems, regardless of the nature of the traveling waves, they will spread throughout the length of the line. When these overvoltage waves meet in a joint or point of discontinuity, multiple reflections will occur in these locations and in this case a wave with two times greater the amplitude than the traveling overvoltage wave, will arise. Such a phenomenon should be considered during the design of high voltage equipment and lines for the coordination of isolation [1]. The analysis of the impact of lightning overvoltages in power systems and effective protection measures increases the reliability of the functioning of the process of transmission of the electric energy in general and reduces the overall costs for implementation and mainte- 
nance of the transmission system of the electric energy. One of the main causes of the power outages for power systems are atmospheric discharges (external overvoltages), with a percentage of approximately $30-40 \%$. External overvoltages are a major source of constraints on the electric power system, both at the distribution level and at the transmission level. The direct impact of lightning poses a dangerous increase in voltage when current discharge pulse propagates through constructive elements. We have analyzed this phenomenon as a very dangerous effect with reference to the power transmission lines. Induced overvoltages are a common and very dangerous effect of atmospheric discharges for electrical equipment. When the lightning strikes the shielding wire or the tower, the flashover can occur. The study of flashovers is very important to assess the performance of the atmospheric discharges, which more strikes phase conductors than the shielding wires [2].

\section{Atmospheric discharges in power systems}

Atmospheric discharges are electrical discharges that come because of the charged cloud. It is well known that lightning clouds are electrically charged, and that the negative charge center is located at the bottom of the cloud, where the temperature is approximately $5^{\circ} \mathrm{C}$. The center of the positive electric charge is located several kilometers above the cloud, where the temperature is usually below $-20^{\circ} \mathrm{C}$. However, in most lightning clouds there is also a number of positive charges localized close to the cloud base, where the temperature is $0^{\circ} \mathrm{C}$ [3]. Negative charges at the bottom of the cloud induce reverse polarity charges on the transmission line. Electrically charged clouds can be discharged directly to the line. If the line is located away from a station or substation, then the overvoltage wave will travel in both directions of the line. The waveform of these overvoltages will be like the current during atmospheric discharge. The discharge current (strike current) $\mathrm{i}$ is divided into equal values in two directions of the phase conductor and gives a traveling wave with a size $u$ :

$$
\mathrm{u}=\frac{1}{2} \mathrm{Zi}\left(\mathrm{e}^{-\alpha \mathrm{t}}-\mathrm{e}^{-\beta \mathrm{t}}\right)
$$

where $\mathrm{Z}$ is the surge impedance of the phase conductor. However, direct lightning strikes on transmission lines are less common than indirect strikes and the effects that cause indirect strikes on the lines are considerably smaller than the effects of direct strikes.

When atmospheric discharge strikes the pole without a shielding wire, then the potential change to the pole and the phase conductor will be:

$$
\mathrm{u}=\mathrm{Ri}+\mathrm{L} \frac{\mathrm{di}}{\mathrm{dt}}+\mathrm{e}_{\mathrm{i}}
$$

Where $e_{i}$ is the induced voltage in the phase conductor due to lightning. If the lightning strikes the shieldeing wire, the overvoltage wave will travel in two directions through the shielding wire. When these waves reach the adjacent towers, they will 
partially have reflected, and the reflective waves will return back to the tower, after half the time between the towers. Other reflections will occur as the waves continue to travel through the shielding wire and reach the other towers. To calculate the resulting voltage and potential change through isolation, the initial period, the first reflection period, the second reflection period and so on should be considered. If the lightning strikes an object close to the line, then charges in line which so far were tied, now will travel almost at the speed of light through the line, to equalize potential at all points of the line. These tied charges cause the line to generate a voltage wave in each direction [4]. For well-designed lines that have shielding wires, most lightning strikes will be stopped by the shielding wire. Stroke current will travel along the shielding wire until it reaches a structure through which it will be conducted to the ground. Since transmission lines and high voltage equipment are protected by surge arresters, which drains the surges rapidly before the insulation is damaged, the surge arrester must operate below the minimum insulation level to withstand the surges. The IEEE provides an imaginary method to calculate the flashovers caused by atmospheric discharges and the level of failure of high voltage lines. The calculation is based mainly on the following parameters: Distribution of maximum currents of atmospheric discharges; ground flash density $\mathrm{N}_{\mathrm{g}}$ through the line; pole geometry (phase position) and grounding resistance [5].

\section{Ground flash density for Kosovo}

The frequency at which the atmospheric discharge will strike the transmission lines will depend on a number of factors, such as the overall level of lightning activity for a region in which the lines are located, physical dimensions, the presence of natural protective objects, etc. The frequency of the occurrence of atmospheric discharges is not easy to measure without any special equipment, such as the lightning localization system. In our case, the data on the frequency of lightning appearances were obtained from observations made at the Meteorological Department and the lightning detection system called Automated Lightning Alarm and Risk Management (ALARM) at Prishtina International Airport "Adem Jashari". This system provides the position and frequency of atmospheric discharges with a suitable presentation of atmospheric discharges, providing cloud to earth and cloud to cloud lightning activities within a 56 $\mathrm{km}$ radius. In Table 1 is presented the number of days with lightning through the years and on average for Kosovo during the period 2003-2016.

One can see that there is an average of 31 days with lightning for the considered period. This number of days with lightning is associated with marked instability and convective clouds.

Atmospheric discharges occur mainly during the summer months when the temperature is high, and the air is humid. It should be noted that the incidence of atmospheric discharges is statistically significant, and it varies significantly from year to year and from season to season. The density of ground lightning, referred to as Ground Flash Density (GFD) or $\mathrm{N}_{\mathrm{g}}$, is defined as the number of atmospheric dis- 
charges that strikes the earth per unit of area and per year. Typically, an average value of a long time of observing days with atmospheric discharge is taken [6].

GFD is defined as a function of TD (days with thunderstorms or keraunic level) or TH (thunderstorm hours). This is important in cases where GFD data from lightning localization systems are not available. The ground flash density can be found using the expression presented below, respectively [7].

$$
\mathrm{N}_{\mathrm{g}}=0.04 \mathrm{TD}^{1.25} \text { flashes } / \mathrm{km}^{2} / \text { year }
$$

The results for ground flash density for Kosovo are presented in Table 2.

Table 1. Number of days with lightning and in average for Kosovo for years 20032016

\begin{tabular}{|l|c|}
\hline \multicolumn{1}{|c|}{ Year } & Number of days with lightning \\
\hline 2003 & 18 \\
\hline 2004 & 25 \\
\hline 2005 & 28 \\
\hline 2006 & 32 \\
\hline 2007 & 30 \\
\hline 2008 & 38 \\
\hline 2009 & 42 \\
\hline 2010 & 28 \\
\hline 2011 & 33 \\
\hline 2012 & 28 \\
\hline 2013 & 30 \\
\hline 2014 & 52 \\
\hline 2015 & 20 \\
\hline 2016 & 31 \\
\hline Average & 31.1 \\
\hline
\end{tabular}

Table 2. Ground flash density for Kosovo for years 2003-2016 and in average

\begin{tabular}{|l|c|}
\hline \multicolumn{1}{|c|}{ Year } & $\begin{array}{c}\text { Ground flash density } \\
\text { (flashes/km }{ }^{2} \text { /year) }\end{array}$ \\
\hline 2003 & 1.5 \\
\hline 2004 & 2.2 \\
\hline 2005 & 2.6 \\
\hline 2006 & 3.0 \\
\hline 2007 & 2.8 \\
\hline 2008 & 3.8 \\
\hline 2009 & 4.3 \\
\hline 2010 & 2.6 \\
\hline 2011 & 3.2 \\
\hline 2012 & 2.6 \\
\hline 2013 & 2.8 \\
\hline 2014 & 5.6 \\
\hline 2015 & 1.7 \\
\hline 2016 & 2.9 \\
\hline Average & 3.0 \\
\hline
\end{tabular}




\section{Modeling and dynamic simulation of metal-oxide surge arresters}

Surge arresters are devices that enable efficient protection of electrical equipment from overvoltages. The model for surge arresters is based on IEEE recommendations and this is actually a frequency-dependent model. Such a model is given in Fig. 1.

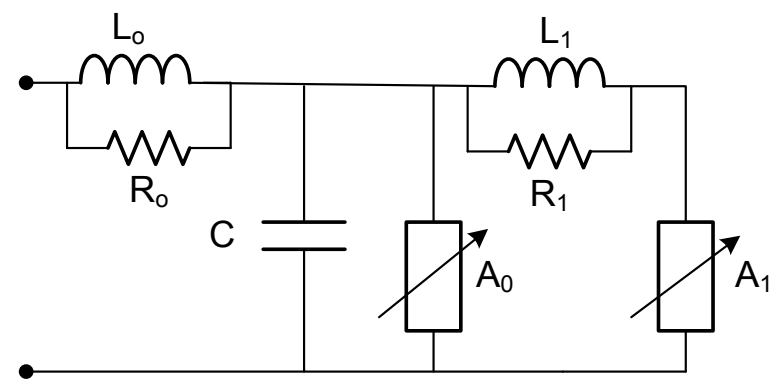

Fig. 1. Frequency-dependent IEEE model

For low-frequency surges, the impedance of the filter will be very small, and therefore $A_{0}$ and $A_{1}$ will be practically connected in parallel. For high-frequency surges, the impedance of the filter will increase, causing a current between the two nonlinear resistors. Due to the impact of $\mathrm{L}_{1}$, the current through $\mathrm{A}_{0}$ increases when the wave front decreases. The V-I characteristic for two nonlinear $\mathrm{A}_{0}$ and $\mathrm{A}_{1}$ resistances, which are separated by an R-L filter $\left(\mathrm{R}_{1}\right.$ and $\left.\mathrm{L}_{1}\right)$, will be obtained from Table 3 and these values will be used for Matlab simulation of $\mathrm{ZnO}$ surge arresters [8]. The surge arrester parameters will be obtained using the IEEE model and the experimental results:

$$
\begin{aligned}
& \mathrm{L}_{1}=15 \frac{\mathrm{d}}{\mathrm{n}}=18.54[\mu \mathrm{H}] \\
& \mathrm{R}_{1}=65 \frac{\mathrm{d}}{\mathrm{n}}=80.34[\Omega] \\
& \mathrm{L}_{0}=0.2 \frac{\mathrm{d}}{\mathrm{n}}=0.2472[\mu \mathrm{H}] \\
& \mathrm{R}_{0}=20 \frac{\mathrm{d}}{\mathrm{n}}=20.47[\Omega] \\
& \mathrm{C}=100 \frac{\mathrm{n}}{\mathrm{d}}=80.9061[\mathrm{pF}]
\end{aligned}
$$

$\mathrm{d}$ is the height of the $\mathrm{ZnO}$ arrester in meters and $\mathrm{n}$ is the number of parallel columns (from the ABB catalog, $\mathrm{d}=1.236 \mathrm{~m}$ and parameter $\mathrm{n}$ is chosen to be 1 ).

A voltage level of $110 \mathrm{kV}$ is chosen for the computer analysis of the line surge arresters, using software package Matlab [9]. These lines have the worst performance regarding atmospheric discharges (See Table 4). 
Table 3. V-I characteristics for nonlinear resistances $\mathrm{A}_{0}$ and $\mathrm{A}_{1}$

\begin{tabular}{|c|c|c|c|}
\hline \multicolumn{2}{|c|}{$\mathbf{A}_{\mathbf{0}}$} & \multicolumn{2}{|c|}{$\mathbf{A}_{\mathbf{1}}$} \\
\hline $\boldsymbol{I}[\boldsymbol{k} \boldsymbol{A} \boldsymbol{]}$ & $\boldsymbol{V}[\boldsymbol{p} . \boldsymbol{u} \cdot \boldsymbol{]}$ & $\boldsymbol{I}[\boldsymbol{k} \boldsymbol{A}]$ & $\boldsymbol{V}[\boldsymbol{p} . \boldsymbol{u} \cdot \boldsymbol{]}$ \\
\hline 0.01 & 1.3 & 0.01 & 1.1 \\
\hline 0.1 & 1.37 & 0.1 & 1.17 \\
\hline 1 & 1.56 & 1 & 1.36 \\
\hline 2 & 1.6 & 2 & 1.4 \\
\hline 4 & 1.66 & 4 & 1.46 \\
\hline 6 & 1.76 & 6 & 1.56 \\
\hline 9 & 1.81 & 9 & 1.61 \\
\hline 10 & 1.84 & 10 & 1.74 \\
\hline 20 & 2.06 & 20 & 1.86 \\
\hline 40 & 2.35 & 40 & 2.15 \\
\hline 50 & 2.5 & 50 & 2.3 \\
\hline
\end{tabular}

Table 4. Outages of transmission lines in Kosovo Power System regarding atmospheric discharges for years 2007-2016 and in average

\begin{tabular}{|c|c|c|c|}
\hline $\begin{array}{c}\text { Element } \\
\text { outages/Year }\end{array}$ & $\begin{array}{c}\text { Transmission } \\
\text { lines } \\
\mathbf{1 1 0}[\mathbf{k V}]\end{array}$ & $\begin{array}{c}\text { Transmission } \\
\text { lines } \\
\mathbf{2 2 0}[\mathbf{k V}]\end{array}$ & $\begin{array}{c}\text { Transmission } \\
\text { lines } \\
\mathbf{4 0 0}[\mathbf{k V}]\end{array}$ \\
\hline 2007 & 42 & 2 & 1 \\
\hline 2008 & 61 & 5 & 1 \\
\hline 2009 & 58 & 0 & 3 \\
\hline 2010 & 74 & 19 & 10 \\
\hline 2011 & 48 & 10 & 7 \\
\hline 2012 & 12 & 7 & 3 \\
\hline 2013 & 49 & 8 & 5 \\
\hline 2014 & 36 & 6 & 3 \\
\hline 2015 & 52 & 4 & 2 \\
\hline 2016 & 29 & 8 & 1 \\
\hline Average & 46.1 & 6.9 & 3.6 \\
\hline
\end{tabular}

The surge arresters for the voltage level $110 \mathrm{kV}$ can be with a maximum voltage of $\mathrm{U}_{\mathrm{m}}=145 \mathrm{kV}$. Based on the ABB surge arresters catalog, the rated voltage for surge arresters, for the direct grounding system is [10]:

$$
\mathrm{U}_{\mathrm{r} 0}=0.72 \times \mathrm{U}_{\mathrm{m}}=0.72 \times 145=104.4 \mathrm{kV}
$$

The surge arrester with rated voltage $U_{\mathrm{r}}=108 \mathrm{kV}$ will be selected. The best option for $145 \mathrm{kV}$ is class 2 arrester, named PEXLIM R type. This arrester has a ratio of the lightning impulse protection level to the rated voltage: $\mathrm{U}_{\mathrm{pl}} / \mathrm{U}_{\mathrm{r}}=2.59$ and this means $\mathrm{U}_{\mathrm{pl}}=280 \mathrm{kV}$ at $10 \mathrm{kA}$. With external insulation withstand $\mathrm{U}_{\mathrm{wl}}=550 \mathrm{kV}$ this surge arrester would give a protective margin $\mathrm{M}_{\mathrm{rl}}=(550 / 280-1) \times 100=96 \%$. If the chosen type of the arrester does not offer the desired protection margins, the selection should be changed by choosing a higher arrester discharge class leading to $U_{p l}$ reduc- 
tion. In cases where the margin is insufficient, we will select the arrester class 3, with the same rated voltage $108 \mathrm{kV}$. Metal oxide surge arresters can be built with one or more parallel columns. In the power systems where large strikes occur, the metal oxide surge arresters are constructed of two or more parallel systems. Currents from atmospheric discharges vary in amplitude and shape. Most lightning strikes from cloud to earth differ from kA to several tenth of kA. Discharges over $100 \mathrm{kA}$ are rare; because the largest reported strike current value is $200 \mathrm{kA}$. The waveform of the current and the corresponding voltage is different for each stroke. The current generator of different shapes is used for testing the overvoltage surge arresters in the laboratory. Based on the IEEE recommendations, overvoltage surge arresters should be tested for $10 \mathrm{kA}$ and $20 \mathrm{kA}$ discharge currents with impulse waveform $8 / 20 \mu \mathrm{s} / \mu \mathrm{s}$ [11].

In Fig. 3 is presented the MATLAB model for the discharge current generator.

The earthed arrester is connected directly to the end of the generator as in Fig. 4.

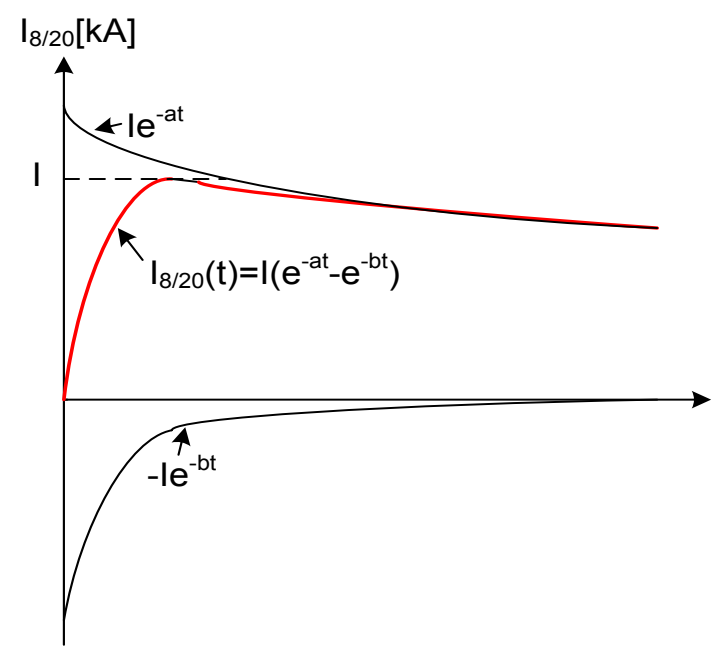

Fig. 2. The exponential form of the current impulse caused by atmospheric discharge

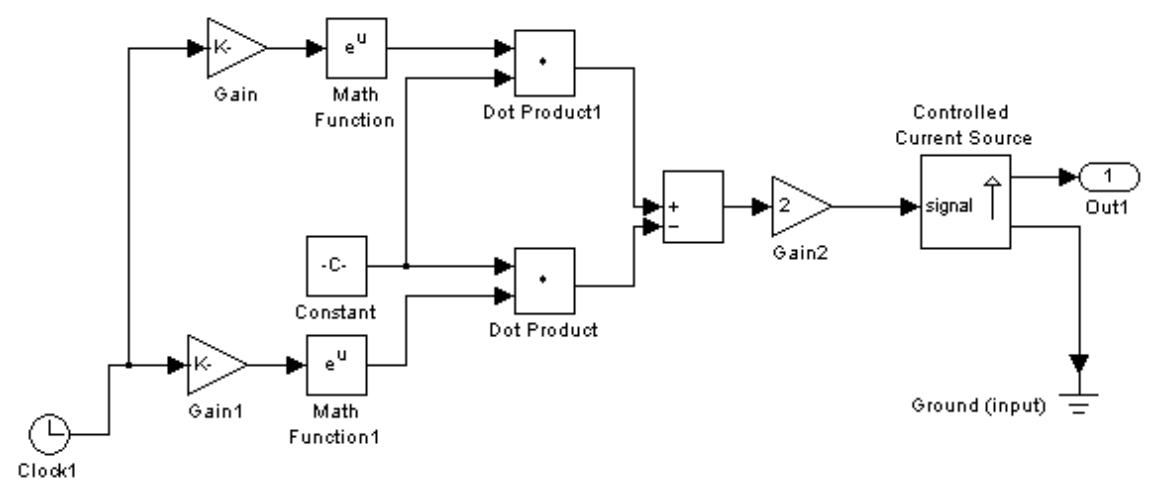

Fig. 3. Model for discharge current generator with possibility of striking amplitude regulation 


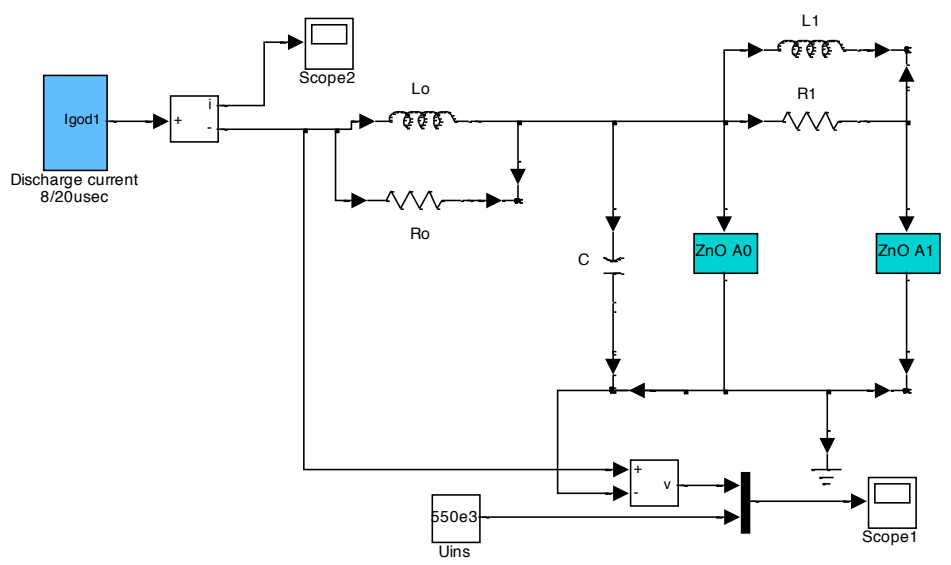

Fig. 4. The simulation model for the performance analysis of $\mathrm{ZnO}$ surge arresters

\section{$5 \quad$ Simulations}

Simulation is done for $10 \mathrm{kA}$ and $20 \mathrm{kA}$ discharge currents. The figures 5 and 6 show relevant results from simulation through Matlab.

From the simulation results (from Fig. 6), it is seen that the remaining voltage $U_{r}=$ $280 \mathrm{kV}$ is almost identical to the residual voltage that the ABB manufacturer guarantees for the class 2 PEXLIM R surge arrester type. The difference between the $550 \mathrm{kV}$ and the remaining voltage $280 \mathrm{kV}$ defines the protective margin of the arrester.

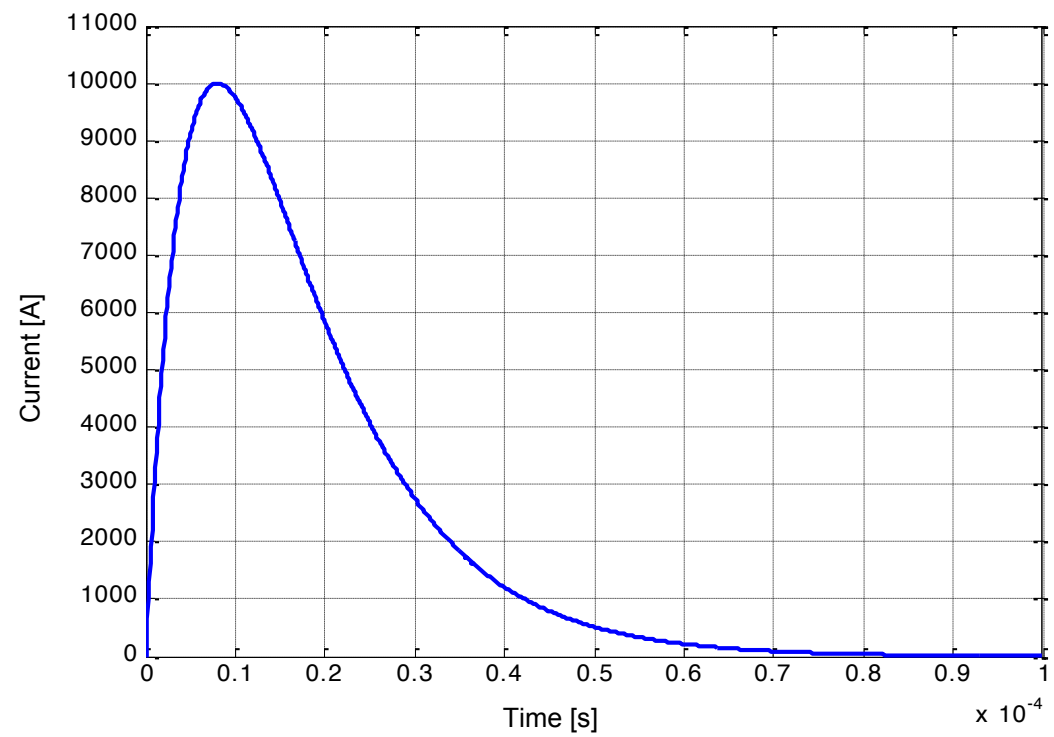

Fig. 5. The discharge current of $10 \mathrm{kA}$ with impulse shape $8 / 20 \mu \mathrm{s} / \mu \mathrm{s}$ 
Paper-Kosovo's Ground Flash Density and Protection of Transmission Lines of The Kosovo Power..

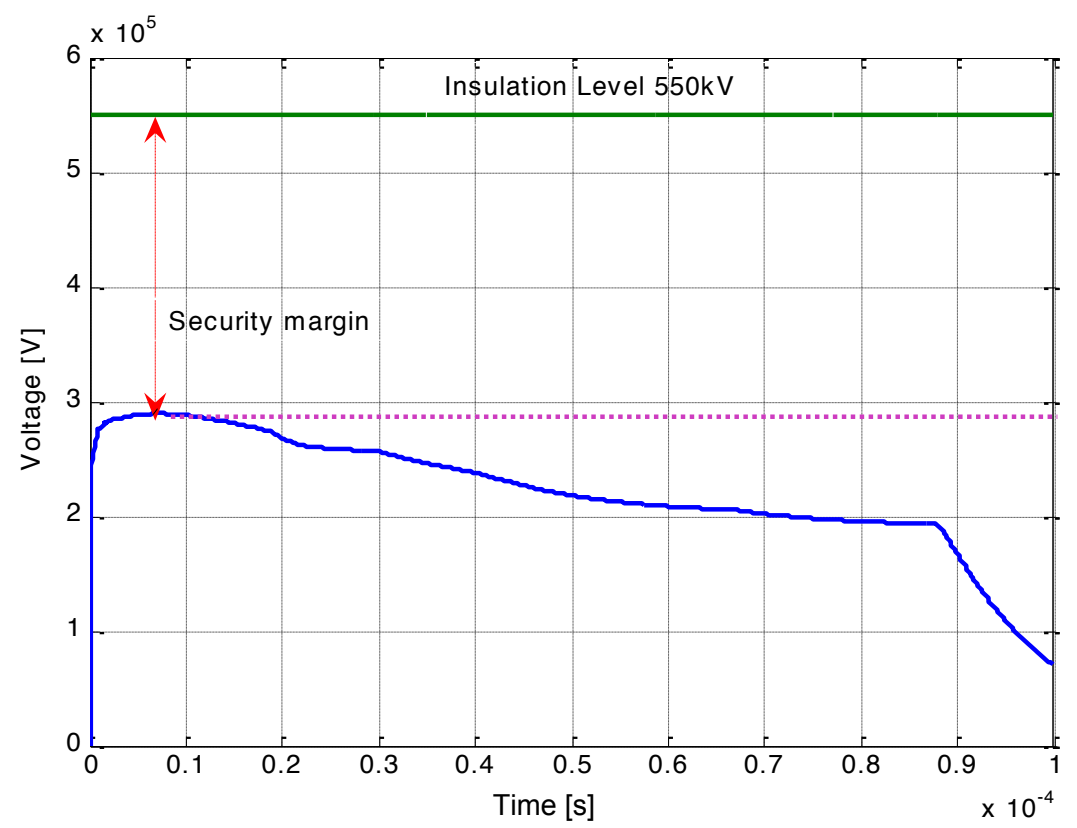

Fig. 6. Residual voltage for discharge current $10 \mathrm{kA}$ with impulse form $8 / 20 \mu \mathrm{s} / \mu \mathrm{s}\left(\mathrm{U}_{\mathrm{r}}=280\right.$ $\mathrm{kV}$ )

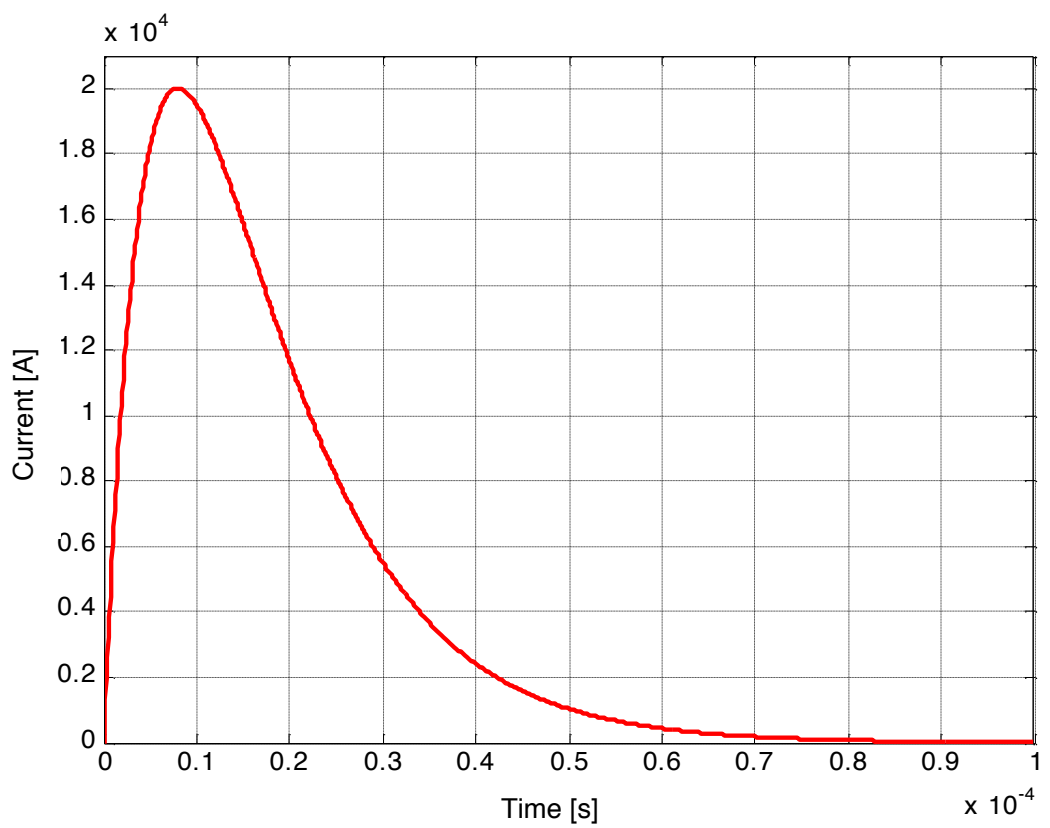

Fig. 7. The discharge current of $20 \mathrm{kA}$ with impulse form $8 / 20 \mu \mathrm{s} / \mu \mathrm{s}$ 


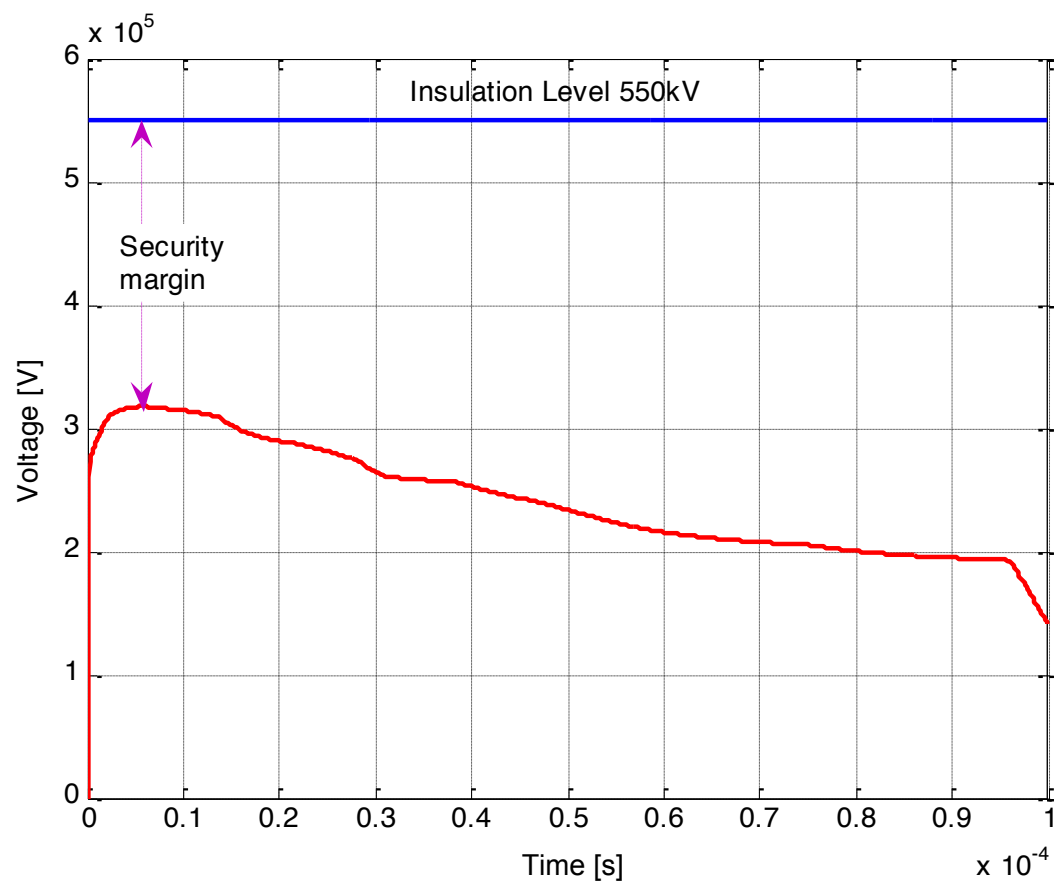

Fig. 8. Residual voltage for discharge current of $20 \mathrm{kA}$ with impulse form $8 / 20 \mu \mathrm{s} / \mu \mathrm{s}\left(\mathrm{U}_{\mathrm{r}}=315\right.$ $\mathrm{kV})$

From the simulation results (from Fig. 8) one can see that residual voltage $U_{r}=310$ $\mathrm{kV}$ is almost identical to the residual voltage that the ABB manufacturer guarantees for the class 2 PEXLIM R surge arrester type. The difference between the $550 \mathrm{kV}$ and the residual voltage $310 \mathrm{kV}$ now is smaller. If this margin does not guarantee efficient protection, then it is preferable to choose a higher surge arrester class, which will increase the protective margin. The simulation results show that the residual voltage is almost identical to the residual voltage that is guaranteed by the manufacturer [6].

\section{Conclusion}

The parameters that are important for calculating the performance of power transmission lines and for calculating various protection methods are the lightning currents and ground flash density. The consequences of lightning strikes on high voltage transmission lines depend on the design and construction of the line, the amplitude and the shape of the lightning current, the position where the lightning strikes and the degree to which the protection is provided with the surge arresters. An accurate model of $\mathrm{ZnO}$ surge arresters has been introduced. It is based on frequency-dependent IEEE model. Knowledge of the frequency of occurrence of lightning strikes, defined as the ground flash density, is of major importance in the design of protection against atmospheric discharges. Since the level of ground flash density in Kosovo is increasing, 
Paper-Kosovo's Ground Flash Density and Protection of Transmission Lines of The Kosovo Power..

this implies that the number of strokes in the transmission lines and other power equipment is increasing also.

\section{$7 \quad$ References}

[1] J. Krasniqi and G. Latifi, "Teknika e tensioneve të larta”, Universiteti i Prishtinës, Prishtinë, pp. 177-186, 1996.

[2] D. Johari, V. Cooray, M. Rahman, P. Hettiarachchi, and M. M. Ismail, "Characteristics of leader pulses in positive ground flashes in Sweden", Electric Power Systems Research, 2016.

[3] G. R. Barry and R. J. Chorley, "Atmosphere, weather and climate", 7-th edition, Routledge, pp. 80-85, 1998.

[4] J. R. Lucas, ”High Voltage Engineering”, 2001.

[5] F. H. Silveira, S. Visacro, and R. E. Souza, "Lightning performance of transmission lines: Assessing the quality of traditional methodologies to determine back flashover rate of transmission lines taking as reference results provided by an advanced approach," Electric Power Systems Research, 2017. https://doi.org/10.1016/j.epsr.2017.01.005

[6] J. Krasniqi and G. Kabashi, "Mbrojtja e fushave të linjave nga mbitensionet përmes shkarkuesve metal-oksid (ZnO)", in ASHAK, Kërkime 14, Prishtinë, 2006.

[7] R. L. L. Grigsby, "Power Systems", CRC Press, New York, 2006.

[8] H. I. H. Ortiz, C. Avendano and F. Roman, "Modeling of metal-oxide distribution surge arresters with an intentionally connected series gap", in 28th International conference on lightning protection ICLP, 2006.

[9] Ch.M.Ong, ”Dynamic Simulation of electric machinery using MATLAB/SIMULINK", Prentice Hall, New Yersey, 1998.

[10] "ABB Surge Arresters Buyer's Guide", Edition 6, ABB, 2008-08.

[11] J. C. Das, "Transients in Electrical Systems-Analysis, Recognition and Mitigation", McGraw Hill, New York, pp. 91-121, 2009.

\section{Authors}

Bahri Prebreza received his Electrical Engineering Degree from University of Prishtina, Kosovo in 1994, in vector methods for analyzing the transient processes in asynchronous motors, Mr.sc. Degree from the University of Prishtina in 2007, in switched reluctance motors and Ph.D. Degree at the Electrical Power Systems Department in the University of Prishtina, in 2014, in lightning overvoltages and their impact in Kosovo Power System. His research interests are electrical machinery, power electronics, automatic regulation and high voltage engineering.

Bujar Krasniqi was born in October 1981. He received his Ph.D. degree in Electrical Engineering from Vienna University of Technology, Austria in 2011. During the academic year 2012-2013 he has been engaged as a guest lecturer, and after that he has become Professor in Faculty of Electrical and Computer Engineering, University of Prishtina, Kosovo. His main research interests are wireless communication, optimization, algorithms, energy efficiency, electrical engineering, etc.

Article submitted 13 January 2018. Final acceptance 23 February 2018. Final version published as submitted by the authors. 